\title{
Optimization of recombinant vaccine antigen dose in mouse model by ELISA and immunophenotyping
}

\author{
Bonam Srinivasa Reddy ${ }^{1,2}$ and Halmuthur M Sampath Kumar ${ }^{1,2}$ \\ ${ }^{1}$ Vaccine Immunology Laboratory, Natural Products Chemistry Division, Indian Institute of Chemical Technology, Hyderabad-500007, India \\ ${ }^{2}$ Academy of Scientific and Innovative Research, CSIR-Indian Institute of Chemical Technology, Hyderabad-500007, India
}

\begin{abstract}
Mass administration of vaccines against particular disease to produce protective immunity is the ultimate goal of developing recombinant vaccine antigens. Preclinical optimization and standardization of antigen dose is highly crucial for the clinical development of vaccines. In this present study, we have optimized the dose of $\mathrm{HBs} A$, Dengue and JEV recombinant antigens, through estimation of antibody titer by ELISA method (IgG, IgG1 and IgG2a) and Flow cytometric immunophenotyping of $\mathrm{CD}^{+}$and $\mathrm{CD}^{+}$surface markers in vivo in BALB/c mice and determined the minimum detectable antigen dose for immunization as well as antibody reactivity.
\end{abstract}

\begin{abstract}
Abbreviations: PBS: Phosphate-Buffered Saline; RPMI-1640: Roswell Park Memorial Institute-1640; FBS: Fetal Bovine Serum; CD: Cluster of Differentiation; IgG: Immunoglobulin G; TMB: 3,3',5,5'-tetramethylbenzidine; APC-Cy7: Allophycocyanin Cy7; FITC: Fluorescein Isothiocyanate; PE: Phycoerythrin; HBsAg: Hepatitis B Virus Antigen; DENV: Dengue Virus Antigen; JEV: Japanese Encephalitis Virus Antigen; Fc: Fragment Crystallizable; FACS: Fluorescence-Activated Cell Sorting; BD: Becton Dickinson.
\end{abstract}

\section{Introduction}

Conventional vaccines are developed by the attenuation or inactivation of pathogens. The antigenic part in the pathogens is responsible for inducing host immune response against pathogens and developing sufficient immunity against the pathogenic antigen is the superior goal for vaccine development. The success of vaccines primarily depends on the ability of antigens producing antibodymediated immunity whereas, managing cell-mediated immunity is important against intracellular organisms [1]. The choice of antigens is determined by their immunological efficacy and safety with or without the use of adjuvants [2]. Whereas the vaccine antigen intricacy may vary based on the state like the whole pathogen either inactivated, attenuated and split/subunit. Due to safety reasons, vaccines based on whole pathogens are being replaced by subunit and recombinant antigens and in this context, protein antigens and their epitopes are produced by the recombinant DNA technologies which make use of DNA sequence coding for the antigenic protein of the pathogen [3]. In view of the fact that antigens obtained abundantly not necessarily be the good vaccine candidates [4]. In order to improve vaccine efficacy, rational preclinical development of recombinant antigens and improved protocols for predicting the immunogenicity of antigens is an important endeavour. The efficacy of majority of the vaccine candidates prepared from purified recombinant antigens and peptides depends on the antigens alone, the success of subunit vaccines also depends on the adjuvants added to vaccine formulations to boost the immune response to the antigen [5,6]. Undoubtedly, investigation of the effect of dose of antigens on murine models before vaccine development is an important goal. Immunization protocols in mice models will integrate the biological complexities of the immune system and gives a maximum prediction of the efficacy as well as adverse effects [7]. In the present study, we have explored three recombinant antigens (HBsAg, JEV and DENV) for dose optimization required for screening the novel vaccine adjuvants or delivery systems.

\section{Materials and methods}

\section{Cell lines and reagents}

Mice: The study protocol related to animal use was approved by the Institutional Animal Ethics Committee (IAEC) of the Council of Scientific \& Industrial Research-Indian Institute of Chemical Technology (CSIR-IICT) (IICT/BIO/TOX/PG/1/02/2013). Female $\mathrm{BALB} / \mathrm{c}$ mice weighing 25-28 g, 7-8 weeks old were obtained from the Center for Cellular and Molecular Biology (CCMB) Hyderabad, India and maintained under standard laboratory conditions (temperature 22 $\pm 2{ }^{\circ} \mathrm{C}$, relative humidity $50 \pm 15 \%, 12: 12$ light/dark cycle). All animals were given access to water and food ad libitum.

\section{Reagents}

Cell culture materials like PBS, RPMI-1640 media, FBS and others were purchased from the Himedia. Recombinant antigen HBsAg, JEV and DENV are purchased from the commercially available source prospecbio, Israel. Goat anti-mouse IgG from BioLegend, San Diego, California and Goat Anti-Mouse IgG1, Goat Anti-Mouse IgG2a from Southern biotech, Birmingham, United States. Cell surface markers, Anti-CD-3-PerCPCy5.5, Anti-CD4-FITC, Anti-CD8-PE antibodies and TMB substrate were obtained from BD Pharmingen, United States.

Correspondence to: Halmuthur M. Sampath Kumar, Academy of Scientific and Innovative Research, CSIR-Indian Institute of Chemical Technology, Hyderabad-500007, India, Tel: +91-40-27191824; Email: sampath@iict.res.in

Key words: recombinant antigen, antibody, immunophenotyping, vaccine adjuvant, hepatitis $B$, japanese encephalitis, dengue

Received: December 18, 2016; Accepted: January 05, 2017; Published: January 09,2017 


\section{Immunization}

6-8 weeks female mice were divided into four groups for each antigen, each consisting of three mice. Animals were immunized subcutaneously with or without recombinant antigen on day 1 . A booster dose was given after two weeks ( $14^{\text {th }}$ day). Sera were collected after two weeks booster dose ( $28^{\text {th }}$ day). (Figure 1$)$

After estimation of antibody titer, efficacious group animals (discussed further) were sacrificed under light ether anesthesia after $28^{\text {th }}$ day. The lymphocytes from spleens were isolated aseptically in RPMI 1640 medium. Briefly, single cell suspensions were prepared by homogenization of spleen between the ends of frosted slides and homogenized cells were passed through $100 \mu \mathrm{M}$ cell strainer. Cells were centrifuged at $2000 \mathrm{rpm}$ for $10 \mathrm{~min}$ at $4{ }^{\circ} \mathrm{C}$. RBC were lysed with $\mathrm{RBC}$ Lysis buffer $(0.5 \mathrm{M}$ ammonium chloride, $10 \mathrm{mM}$ potassium bicarbonate and $0.1 \mathrm{mM}$ disodium ethylene diamine tetraacetic acid, $\mathrm{pH}$ 7.2) for 5 min at $4{ }^{\circ} \mathrm{C}$ or 90 seconds at room temperature. Lymphocytes obtained were then washed twice with PBS and cell density was calculated by using the trypan blue exclusion method.

\section{Estimation of antigen-specific antibody titer}

Sera was collected from the retro-orbital plexus of the treated groups on the $28^{\text {th }}$ day is subjected to measure antigen-specific IgG, IgG1, and IgG2a antibodies by indirect ELISA [8]. In brief, ELISA 96 well plates were coated with $100 \mu \mathrm{L}$ antigen solution (indicated concentration of antigen in $50 \mathrm{mM}$ carbonate-bicarbonate buffer, $\mathrm{pH}$ 9.6) for overnight at $4{ }^{\circ} \mathrm{C}$. After bringing the plates to room temperature, washed the wells three times with PBST (PBS containing $0.05 \%$ (v/v) Tween 20), and then blocked with $1 \% \mathrm{FBS}$ at $37^{\circ} \mathrm{C}$ for $1 \mathrm{~h}$. After three washings, $100 \mu \mathrm{L}$ of serially diluted sera samples in $1 \%$ FBS or $1 \%$ FBS as control was added to triplicate wells. The plates were then incubated for $2 \mathrm{~h}$ at $37^{\circ} \mathrm{C}$, followed by 3 times of washing. Aliquots of $100 \mu \mathrm{L}$ of rabbit anti-mouse IgG horseradish peroxidase conjugate diluted 1:4000, goat anti-mouse IgG1 peroxidase conjugate $1: 3000$ and IgG2a peroxidase conjugate 1:3000 with $1 \%$ FBS were added to each plate. The plates were further incubated for $2 \mathrm{~h}$ at $37^{\circ} \mathrm{C}$. After washing, the peroxidase activity was assayed as following: $100 \mu \mathrm{L}$ of TMB substrate solution (1:1, Reagent A and Reagent B) was added to each well. The plates were incubated for $10 \mathrm{~min}$ at $37^{\circ} \mathrm{C}$, and enzyme reaction was terminated by adding $50 \mu \mathrm{L} /$ well of $2 \mathrm{~N} \mathrm{H}_{2} \mathrm{SO}_{4}$. The optical density was measured in an ELISA reader at $450 \mathrm{~nm}$. ELISA assays were performed on the same day of sample collection for all of the samples.

\section{Immunophenotyping}

Lymphocytes isolated in the above procedure was used for immunophenotyping. Slightly modified procedure of Colovai A et al., was used. In brief, $5 \times 10^{5}$ cells from all treated groups were taken into the $\mathrm{BD} 5 \mathrm{~mL}$ polystyrene tube. $1 \mu \mathrm{L}$ of Fc block was added to the cells and incubated for $15 \mathrm{~min}$. The cells were harvested and centrifuged at $300 \mathrm{~g}$ for $5 \mathrm{~min}$ at $4{ }^{\circ} \mathrm{C}$. Saturating amounts of allophycocyanin cy7 (APCCy7)-CD3, fluorescein isothiocyanate (FITC)-CD4 and phycoerythrin (PE)-CD8 conjugated antibodies were added to the cells and incubated for $45 \mathrm{~min}$. After incubation washout the unbound fluorochome and suspend the cells in the sheath fluid for FACS analysis [9].

\section{Statistical analysis}

The data was analyzed with the Prism software (GraphPad, San Diego, CA, USA). Data were expressed as mean \pm SD. and statistical analysis was carried out using one-way ANOVA (Bonferroni correction multiple comparison test). The grouped values are presented as mean \pm $\mathrm{SD}$ and significant differences presented as ${ }^{* * *} P>0.0001,{ }^{* *} P>0.001$ and ${ }^{\star} P>0.01$ versus UT group.

\section{Results}

Ourgoal was to determine the minimal effective dose of recombinant viral antigens such as HBsAg, DENV and JEV expressed on bacterial systems were obtained from the commercial source. In vivo evaluation was done to determine their antigenicity in mice with three different doses. Resolving the correct dose to induce optimum antibody response without fail is indispensable. In the present study our traditional two doses vaccination protocol (Figure 1) was followed to evaluate their efficacy in terms of humoral (IgG) and cell-mediated immune response $\left(\mathrm{CD}^{+}\right.$and $\left.\mathrm{CD} 8^{+}\right)$[10]. Lower antigen doses are insufficient to stimulate antibody response, whereas higher antigen doses trigger hypersensitivity reaction. Immunoreactivity of the recombinant antigens against subtypes IgG1 and IgG2a were assessed from the sera. However, it is clear that choosing an optimum dose mainly depends on the type of antigen, type of its preparation, production and route of administration. Selection of antigens for immunization and coating (for ELISA) previous studies on recombinant antigens i.e., HBsAg, DENV and JEV support our study [11-15]. The humoral immune response in terms of antigen-specific IgG response amongst all groups with HBsAg, DENV and JEV has paved way for fixing the optimum dose for each of these antigens based on which, the subtypes IgG1 and IgG2a responses were measured in the same optimum concentrations.

However, this study also helped us to establish the type of immunity produced by the antigens i.e., IgG1:Th2 and IgG2a:Th1. HBsAg immunized with 1,5 and $10 \mu \mathrm{g} /$ dose against $1 \mu \mathrm{g} / \mathrm{mL}$ coating did not show any significant antibody production. Whereas $\mathrm{HBsAg}$ immunized with 5 and $10 \mu \mathrm{g} /$ dose against $4 \mu \mathrm{g} / \mathrm{mL}$ has shown increased antibody production. Moreover, HBsAg with 5 and $10 \mu \mathrm{g} /$

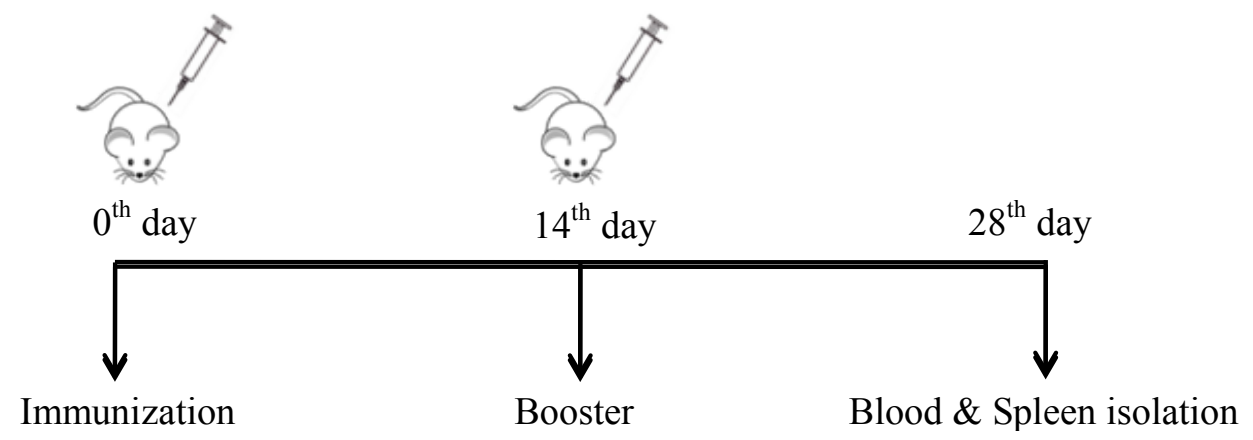

Figure 1. Experimental design for the immunization. 
dose against $8 \mu \mathrm{g} / \mathrm{mL}$ of antigen coating in ELISA has shown profound antibody response. Whereas HBsAg with $5 \mu \mathrm{g} /$ dose against $8 \mu \mathrm{g} / \mathrm{mL}$ of antigen coating in ELISA has been fixed as optimum dose, by taking into consideration, the difficulty involved in the preparation of larger batches of antigens. IgG1 and IgG2a data (Figure 2b) revealed that HBsAg is inducing Th2 biased response (increased $\operatorname{IgG} 1$ titer). In the case of DENV, the mice immunized with 1,5 and $10 \mu \mathrm{g} /$ dose of antigen induced significant antibody titer against 1.5 and $3 \mu \mathrm{g} / \mathrm{mL}$ (Figure 3a) of antigen coating in ELISA. Moreover, at $1.5 \mu \mathrm{g} / \mathrm{mL}$ of antigen coating for ELISA, dose dependent response was observed. However, coating of $3 \mu \mathrm{g} / \mathrm{mL}$ antigen in 5 and $10 \mu g$ dose, saturation of IgG titer was observed. This data indicates that $1 \mu \mathrm{g} /$ dose against $1.5 \mu \mathrm{g} / \mathrm{mL}$ of DENV antigen coating in ELISA was a superior option for antibody subtype analysis. IgG1 and IgG2a graph (Figure $3 \mathrm{~b}$ ) revealing that DENV antigen is inducing Th2 type antibody response (Increased IgG1 titer). In case of JEV, mice immunized with 1,5 and $10 \mu \mathrm{g} /$ dose has shown significant antibody titer against 0.5 and $2 \mu \mathrm{g} / \mathrm{mL}$ of JEV antigen coating in ELISA. Moreover, at both 5 and $10 \mu \mathrm{g} /$ dose of an antigen against antigen coating in ELISA with 0.5 and $2 \mu \mathrm{g} / \mathrm{mL}$, saturation of antibody titer was observed (Figure 4a). Based on the above data it is clear that $1 \mu \mathrm{g} /$ dose of JEV antigen against $0.5 \mu \mathrm{g} / \mathrm{mL}$ of antigen coating in ELISA was selected for antibody subtype analysis. IgG1 and IgG2a graph in this case, revealed that the respective JEV antigen is inducing Th1 type antibody response (Increased IgG2a titer) (Figure 4b). Effect of antigens on cell-mediated immunity, particularly $\mathrm{CD} 4^{+}$and $\mathrm{CD} 8^{+}$ was observed at the same optimum dose for all three antigens and results revealed increased expression of $\mathrm{CD}^{+}$and $\mathrm{CD} 8^{+}$(Figure 5) among all treated groups when compared to untreated (Figure 2-5).
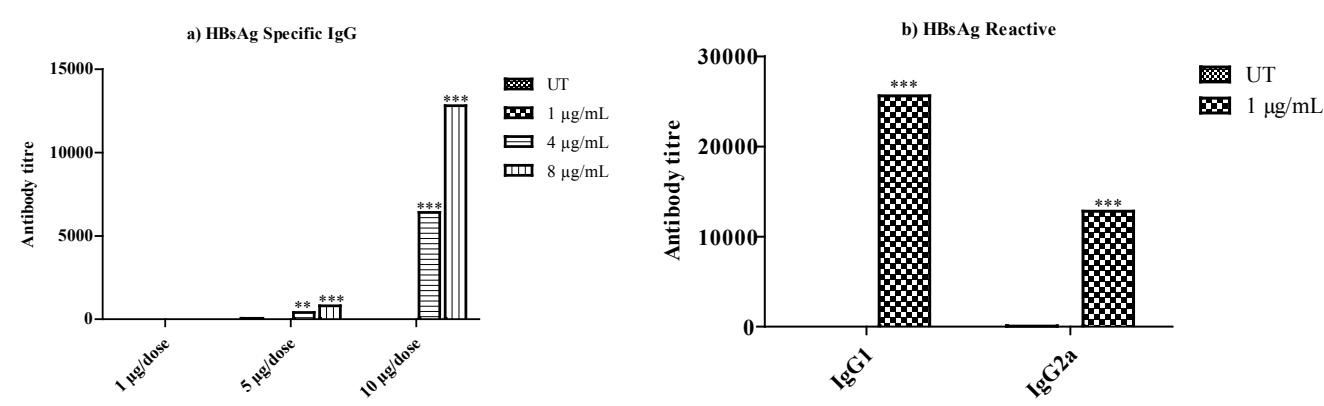

Figure 2. Estimation of HBsAg-specific antibody: a) Mice were vaccinated with doses of 1,5 and $10 \mu \mathrm{g} /$ dose. Two weeks after booster vaccination blood was collected from the retro-orbital plexus and serum was separated for antibody estimation by ELISA. Antigen at 1, 5 and $8 \mu \mathrm{g} / \mathrm{mL}$ in carbonate buffer was used to coat in 96 well plates (100 $\mu$ L/well) for titration. $\mathrm{b}$ ) Mice $5 \mu \mathrm{g} /$ dose group sera were used against $1 \mu \mathrm{g} / \mathrm{mL}$ coating for immunoreactivity of IgG1 and IgG2a.
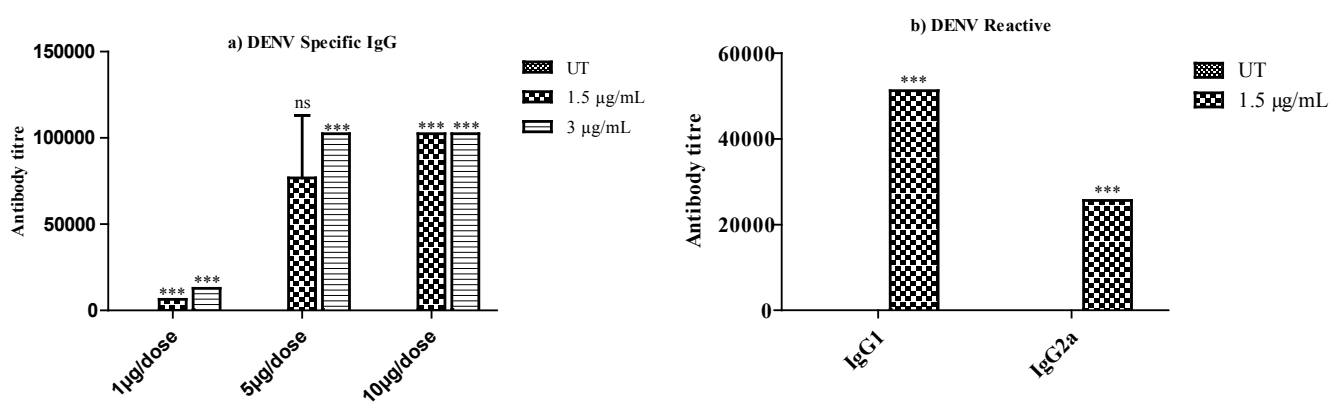

Figure 3. Estimation of Dengue specific antibody: a) Mice were vaccinated with doses of 1,5 and $10 \mu \mathrm{g} /$ dose. Two weeks after booster vaccination blood was collected from the retro-orbital plexus and serum was separated for antibody estimation by ELISA. Antigen at 1.5 and $3 \mu \mathrm{g} / \mathrm{mL}$ in carbonate buffer was used to coat in 96 well plates (100 $\mu \mathrm{L} / \mathrm{well})$ for titration. b) Mice $1 \mu \mathrm{g} /$ dose group sera were used against $1.5 \mu \mathrm{g} / \mathrm{mL}$ coating for immunoreactivity of IgG1 and IgG2a.
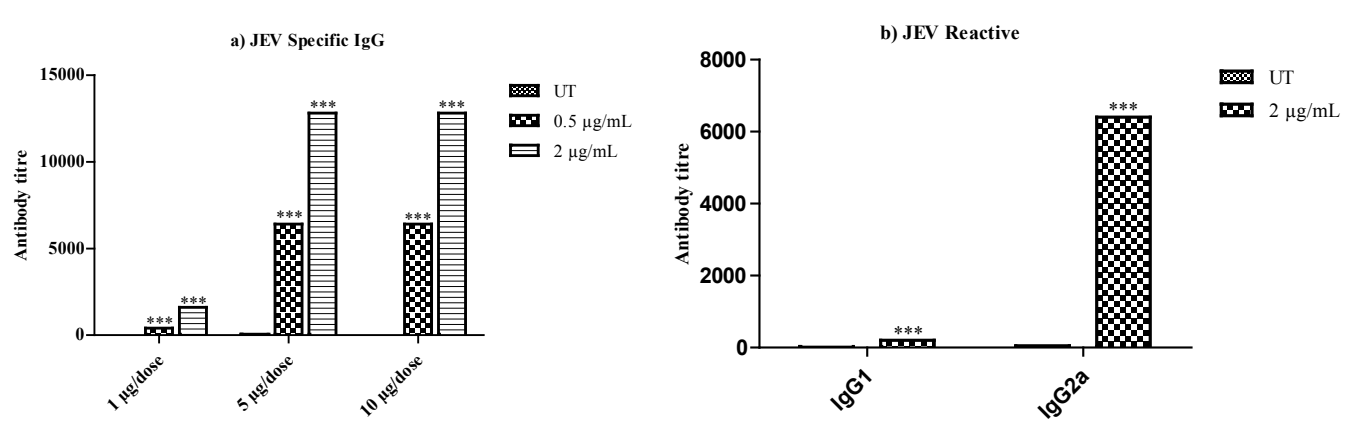

Figure 4. Estimation of JEV specific antibody: a) Mice were vaccinated with doses of 1,5 and $10 \mu \mathrm{g} / \mathrm{mL}$. Two weeks after booster vaccination blood was collected from the retro-orbital plexus and serum was separated for antibody estimation by ELISA. Antigen at 0.5 and $2 \mu \mathrm{g} / \mathrm{mL}$ in carbonate buffer was used to coat in 96 well plates (100 $\mu \mathrm{L} / \mathrm{well})$ for titration. $\mathrm{b}$ ) $\mathrm{Mice}$ $1 \mu \mathrm{g} /$ dose group sera were used against $2 \mu \mathrm{g} / \mathrm{mL}$ coating for immunoreactivity of IgG1 and IgG2a. 

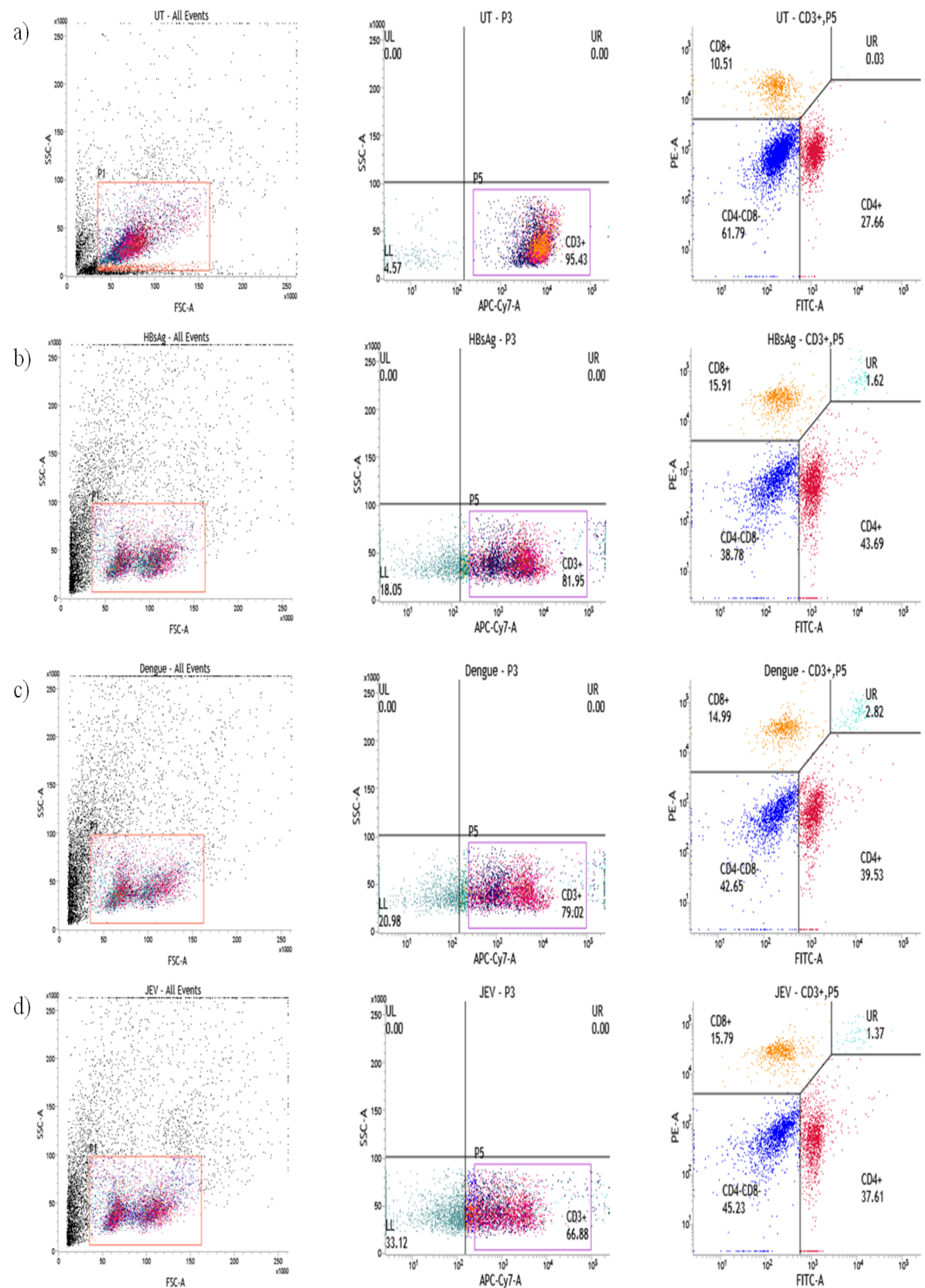

Figure 5. Activation of $\mathrm{CD}^{+}$and $\mathrm{CD}^{+} \mathrm{T}$ cells from vaccinated mice: Splenocytes were isolated from mice after 2 weeks of booster immunization and lymphocytes were stained with APCCy7-conjugated anti-mouse CD3, FITC-conjugated anti-mouse CD4 and PE-conjugated anti-mouse CD8 antibodies and measured by flow cytometry. Representative dot plots for Untreated (UT) (Figure 5a), HBsAg (Figure 5b), DENV (Figure 5c) and JEV (Figure 5d) were obtained by collecting 100,000 cells by flow cytometry. The expressions of CD4 $4^{+}$and CD8 ${ }^{+}$T cells were significantly increased in compared with untreated controls.

\section{Discussion}

To develop and formulate a proper vaccine against a specific disease, efficacy of the antigen should be known and each antigen is different from their conformational, stability as well as mode of action. It is prerequisite to find out the exact dose of antigen for vaccine development which needs to be optimized in preclinical settings in an appropriate animal model. However, based on the type of antigen and it's reactivity many animal models such as dogs, baboons, guinea pigs, mice and some avian species etc. are available to determine the efficacies. Among the all animal models murine model has been used to develop proof of concept studies as mice immune system is similar to humans and thus, targeting specialized immune cells and developing 
models against specific disease are uncomplicated [7]. Furthermore, the dose optimization studies on human specific disease antigens viz., Dengue, Hepatitis and Japanese Encephalitis covered in the present work is not reported elsewhere and the data helps in future preclinical and clinical development of vaccines.

As part of our ongoing research on, development of novel vaccine adjuvants we undertook the study on the dose optimization of the specific antigen of human viral infections such as Dengue, Hepatitis and Japanese encephalitis, which is an essential qualification for taking up disease screening of efficacy of new adjuvant entities against these recombinant viral antigens. The dose response studies carried out here help us to assess the immune response upon various antigen challenge in mouse model as it is well documented that vaccines having cellmediated immunity along with humoral immunity is the utmost important against intracellular pathogens [16-19].

\section{Conclusion}

Evaluation of novel recombinant antigens (HBsAg, DENV and JEV) was carried out in vivo in BALB/C mice to determine the sensitivity and efficacy of antigens under preclinical setting. This study not only interpreted the type of immunity (Th1 or Th2) produced by the antigens but also illustrated the fate of antigens on cell-mediated immunity $\left(\mathrm{CD}^{+}\right.$and $\left.\mathrm{CD}^{+}\right)$. These basic findings will be useful to screen novel molecules for their adjuvant activity against the diseasespecific antigens.

\section{Acknowledgments}

This work was supported by the CSIR- $12^{\text {th }}$ five year plan projectDENOVA (Development of Novel Vaccine Adjuvants, CSC0205). We thank our lab colleagues for valuable discussion.

\section{Conflict of interest}

The authors declare that they have no conflict of interest.

\section{References}

1. Nascimento I, Leite L (2012) Recombinant vaccines and the development of new vaccine strategies. Brazilian Journal of Medical and Biological Research 45: 11021111. [Crossref]

2. Knudsen NPH, Olsen A, Buonsanti C, Follmann F, Zhang Y, et al., (2016) Different human vaccine adjuvants promote distinct antigen-independent immunological signatures tailored to different pathogens. Sci Rep 6.

3. Strugnell R, Zepp F, Cunningham A, Tantawichien T (2011) Vaccine antigens. Perspectives in Vaccinology 1: 61-88.
4. Flower DR (2008) Vaccines: their place in history. Bioinformatics for Vaccinology 1-54.

5. Moreira GM, Salvarani FM, da Cunha CE, Mendonça M, Moreira ÂN, et al., (2016) Immunogenicity of a Trivalent Recombinant Vaccine Against Clostridium perfringens Alpha, Beta, and Epsilon Toxins in Farm Ruminants. Sci Rep 6: 22816. [Crossref]

6. Li W, Joshi MD, Singhania S, Ramsey KH, Murthy AK (2014) Peptide Vaccine: Progress and Challenges. Vaccines (Basel) 2: 515-536. [Crossref]

7. Schunk MK, Macallum GE (2005) Applications and optimization of immunization procedures. ILAR J 46: 241-257. [Crossref]

8. Nalla N, Pallavi P, Reddy BS, Miryala S, Kumar NV, et al., (2015) Design, synthesis and immunological evaluation of 1,2,3-triazole-tethered carbohydrate-Pam3Cys conjugates as TLR2 agonists. Bioorg Med Chem 23: 5846-5855. [Crossref]

9. Colovai AI, Giatzikis C, Ho EK, Farooqi M, Suciu-Foca N, et al., (2004) Flow cytometric analysis of normal and reactive spleen. Mod Pathol 17: 918-927. [Crossref]

10. Bhunia D, Pallavi PM, Bonam SR, Reddy SA, Verma Y, et al., (2015) Design, Synthesis, and Evaluation of Novel 1,2,3-Triazole-Tethered Glycolipids as Vaccine Adjuvants. Arch Pharm (Weinheim) 348: 689-703. [Crossref]

11. Sidiq T, Khajuria A, Shafi S, Ismail T, Kumar HS, et al., (2013) Efficacy evaluation of two synthetic lysine lipidated tripeptides as vaccine adjuvants against HBsAg. European journal of pharmacology 705: 68-78.

12. Audibert FM, Przewlocki G, Leclerc CD, Jolivet ME, Gras-Masse HS, et al., (1984) Enhancement by murabutide of the immune response to natural and synthetic hepatitis B surface antigens. Infect Immun 45: 261-266. [Crossref]

13. Clements DE, Coller BA, Lieberman MM, Ogata S, Wang G, et al., (2010) Development of a recombinant tetravalent dengue virus vaccine: immunogenicity and efficacy studies in mice and monkeys. Vaccine 28: 2705-2715. [Crossref]

14. Wu SC, Lin YJ, Yu CH (2003) Baculovirus-insect cell expression, purification, and immunological studies of the full-length Japanese encephalitis virus envelope protein. Enzyme and microbial technology 33: 438-444.

15. Rauthan M, Kaur R, Appaiahgari MB, Vrati S (2004) Oral immunization of mice with Japanese encephalitis virus envelope protein synthesized in Escherichia coli induces anti-viral antibodies. Microbes Infection 6: 1305-1311. [Crossref]

16. Kirimanjeswara GS, Olmos S, Bakshi CS, Metzger DW (2008) Humoral and cellmediated immunity to the intracellular pathogen Francisella tularensis. Immunological reviews 225: 244-255. [Crsooref]

17. Healey GD, Elvin SJ, Morton M, Williamson ED (2005) Humoral and cell-mediated adaptive immune responses are required for protection against Burkholderia pseudomallei challenge and bacterial clearance postinfection. Infection and immunity 73(9): 5945-5951.

18. Fouts TR, Bagley K, Prado IJ, Bobb KL, Schwartz JA, et al., (2015) Balance of cellular and humoral immunity determines the level of protection by HIV vaccines in rhesus macaque models of HIV infection. Proceedings of the National Academy of Sciences 112(9): E992-E999.

19. Shearer GM, Clerici M (1997) Vaccine strategies: selective elicitation of cellular or humoral immunity? Trends Biotechnol 15: 106-109. [Crossref]

Copyright: (C2017 Bonam SR. This is an open-access article distributed under the terms of the Creative Commons Attribution License, which permits unrestricted use, distribution, and reproduction in any medium, provided the original author and source are credited. 